Chemical Synonyms (Excerpta Medica)

Meyler. L.: Sido Effects of Drugs, 1958. (Excerpta Medica Foundation)

\section{9. カナダ}

Reynolds, A.K., Randall, L.O.: Morphine and Allied Drngs (Vniv. of Toronto Pr.)
Soovillés, A.K., Raudrel, L.O.: Morphine and Allied Drngs (Univ. of Toronto Pr.)

10. ホンコン

Read, B.E.: Chiness plants and vegtable Withillus. (Hongkong)

\title{
薬理学とその文献 (III)
}

\section{B 雑 誌}

\section{1. 日本}

\section{a. 緗説, 抄録, 索引誌}

医学文献総譼，医学原著索引，医学のあゆみ 医学輯録, 医学の進歩, 医学輯覽, 医学綜覧 医学綜報, 医学中央雑誌, 医理学文献題目索 引集，医事及雑誌索引，結核文献の抄録速報 結核研究の進歩, 航空医学綜説, 化学総覧, 内外新薬文献抄総覽, 日本医師会雑誌, 日本 内科小坚科中去雑誌, 日本歯科文献年報, 内 分泌のつどい，産婦人科の進少，雑誌総覽， 全国公私薬研究機関話験研究項目要覽, Japan Science Review, Medical Science.

\section{b. 雑誌（原著および綜説）}

a) 愛知医学会雑誌, アレルギ一時報, ア レルギー

Abhandlung aus dem Pharmakologisch Institut der Mediz!nische Akademie zu Kieto, Abstracts from Rickwagaku-syo-iho (Bulletin of the Institute of Physical and chemical research),

Acta Japonica medicinae tropicalis. (Institute for research in tropical medicine. Taihoku University),

Acta Medica et Biologica, Acta Medica Kagoshimaensis

Acta Medica nagasakiensia, Acta Medicinalia in Keijo, Acta Medicine Okayama, Acta Scholae medicinalis universitatis im- perialis in Kioto,

Acta Tuberc. Jay, Acta Viterinaria Japonica, Annales Paediatrica Japonica,

Ann. Rep. of Res. Inst. of Environ. Med., Nagoya Univ, Annals of Tuberculois,

Annotationes zoologicae japonenses. (Zoological society of Japan),

Annal reports. Taihoku teikoku daigaku. Rinogakubu,

Annual repost of the Central sanitary bureau attached to the Home dept. of the Imperial japanese government Tokyo,

Arbeiten aus dem Biochemischen Institut der Aichi medizinischen Universitat, Nagoya,

b）バイエル時報, 微生物学連合学会演説 抄録，徽毒，徽毒の診断と治療，病理と治療 病理学雑誌, ビタミン

Bull. of the Agricultural chemical societe of Japan.

Bull. of the Heart Institute.

Bull. of the Osaka Med. Sch.

Bull. of the Univ. of Osaka Prefecture.

Bull. of Pharm. Res. Inst.

The Bull. of Tokyo Med. \& Dent. Univ. Bull. Yamaguchi Med. Sch.

c）千葉医学会雑誌，千葉大学腐敗研究所 報告, 朝鮮医学会雑誌, 朝鮮医報

Chem \& Pharmaceut. Bull.

Collected papers in physiol. and biolog. physicochemi. Kyoto Imperial University. 
Collected papers of the Inst. of med. chom. of Tokyo Imp. Univ.

Contributions, Tyuo kenkyu-syo, Eisei-bu, Taiwan, Taihoku.

Cytologia

d）同仁会医学雑誌，第一薬報，同仁会雑 誌，大日本獣医会誌

e）衛生技術颜研究報告，衛生試験所報告 栄養学雑誌

Endocrinologia Japonica.

f）福島医学, 福島医学雑誌, 福岡医学雑 誌

Folia psychiat. et neurolog. jap. Niigata.

Fukushima J. of Med. Sci.

g）外科, 外科の領域, 癌, 癌の臨床, グ レンツゲビード, 岐皁医科大学紀要, 岐㚖薬 科大学紀要, 原著広島医学 (広島医学原著号 改題), 腿科臨

Gumma J. of Med. Sci.

h) 弘前医学, 広島医学, 広島医科大学論 文集, 北海道医学雑誌, 北海道産婦人科学会 雑誌, 北陸医学会々誌, 北越医学会雑誌, 兵 䡛医学, ホルモント臨床, 本草, 皮膚と泌尿 阪大微生物研究所年報,

Hiroshima J. Med. Sci.

i) 医学研究, 医学々生物学, 医学与薬学 医界公論, 医理学新報, 医療, 医人, 医事新 報, 岩手医学雑誌

Jap. Heart J.

Jap. J. of Exp. Med.

Jap. J. of Med. Sci. \& Biol.

The Jap. J. of Tuberculosis.

Jap. J. of Vetz. Res.

Jap. J. of Ophthalmol.

Jap. J. of Pharmacol.

Jap. J. of Physiol.

Jap. Literatur zur Tuberkuloseforsch. Kyoto,

J. of biochem. (Med. Dept. of the Tokyo Imp. Univ.).
J. of biophys (Physiol. Inst. Tokyo Imp. Univ.).

J. of biophys (Physiol. Inst. Tokyo Imp. Univ.).

J. of exper. therap. (Juntendo inst. for med. res. Tokyo.),

The J. of Gen. and Appl. Microbiol.

J. of med. Coll. in Keijo.

J. of Oriental Med.

J. of Nihon Univ. Sch. of Dentistry.

J. of the Sizenkagaku Kenkyusyo.

J. of Antibiotics. (Ser. A)

J. of Antibiotics. (Ser. B)

J. of Jap. Obstet. \& Gynecol. Soc.

The J. of Vitaminol.

Jikeikai Med. J.

k）科学, 科学研究所報告, 化学の領域, 化学療法, 化学療法研究所鲁報, 鹿児島医学 專門学校学術報告, 鹿児島医学雑誌, 鹿児島 医科大学紀要, 環境医学研究所年報, 金沢医 科大学結核研究所年報, 金沢大学薬学部研究 年報, 漢方, 漢方と漢薬, 慶応医学, 京城医 学紀要京城歯科医学会雑誌, 京城医学專門学 校紀要, 京城帝国大学医学部杉原薬理教室研 究報告，結核，結核彙報，結核研究，結核の 臨床，血清学免疫学雑誌，北関東医学，基璴 と臨床, 国家医学雑誌, 国家医学会雑誌, 北 野病院業績報告, 北里実験医学, 神戸医科大 学紀要，呼吸と循環，口腔病学会雑誌，口腔 外科, 北立国京医学院研究成績索引，国立北 京大学医学院論文集, 国立北京大学医学杂隹誌 国立中山大学医科集刊, 公衆術生学雑誌, 公 衆衛生院研究報告, 交通医学, 熊本医学会雑 誌, 熊本大学体質医学研熊所報告, 熊本同門 会誌，久留米医学会雑誌，倉敷中央病院年報 薬の知識, 胸部外科, 京都府立医学軸門学校 々友会雑誌，京都府立医科大学雑誌，京都医 学雑誌, 京都医学会雑誌, 京都大学結核研究 所紀要, 京都歯科医学会及誌, 京都薬科大学 学報, 京都帝国大学医学部紀要, 京都陪国大 学医学部生理学教室業績, 九大医報, 九大薬 法, 九州大学結核研究所紀要, 九州医学会々 
誌，九州歯科医学会雑誌，九州蒾科学会雑誌 寄笔虫学雑誌, 抗酸菌病研究雑誌, 抗菌物質 研究, 抗菌物質研究雑誌, 国立栄養研究所研 究報告, 感光色素, 国立公媓衛生院研究報告 国立衛生試験所報告, 国立予防衛生研究所年 報, 国立遺伝研究所年報, 近畿大学薬学部紀 要, 共立薬科大学研究年報, 関西医科大学雑 誌, 神夸川県立衛生研究所年報

Keio J. of Med.

Keijo J. of Med. Keijo. (Seoul)

Kitasato each. of exper. Med.

Kumamoto Med. J.

Kumamoto Pharm. Bull.

The Kurume Med. J.

Kyushu J. of Med. Sci.

The Kobe J. of the Med. Sci.

m) 三重医学，明友薬郕誌，麻酔，満洲獣

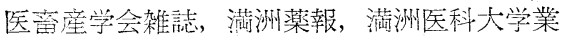
績集，满洲医学雑誌，モグンテラピー

Memoirs of the Kitano hospital, Osaka.

Mitteilungen aus d. Med. Akad. (Fachschule, Hochscule) zu Keijo.

Mitteilungen aus d. Med. Fak. der Kaiserl.

Evashu Univ. Fukuoka.

Mitteilungen aus der Med. Fak. der Kaiserl.

Univ. zu Tokyo.

Monographs. Reprint series. Saito ho-on Kai Sendai.

Monographs. Res. bull. Saito ho-on Kai. Medical Bulletin of the Kagoshima Univ. Med. J. of Osaka Univ.

Med. time.

Med. J. of Shinshu Univ.

Mie Med. J.

n）長野湿医学会雑誌，長崎医学会锥諰， 長䐀医科大学紀要, 内科の領域, 严古屋医学 名声屋市立医科大学杂誌，名古屋市立大学薬 学部紀要，名古屋市主大学医学会雑誌，名古 屋帝国大学医学部蔝理教室，名古屋大学環境 医学研究所年報, 内分泌と代謝, 内外医報, 内外治療, 内科及小昌科，南方医薬研究䝳料 南方医学論叢, 南漛洲医学会雑誌, 奄良県立

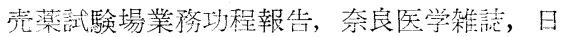

本微生物学病理学雑誌, 日本病理学会雑誌, 日本伝染病学会誌，日本不妊学会雑誌，日本 整形外科学会雑誌，日本消化機病学会雑誌， 日本外科学会雑誌, 日本外科室函, 日本衛生 学雑誌, 日本法医学雑誌, 日本婦人科学会雑 誌，日本医学専門学校雑誌，日本医科大学雑 誌，日本口腔医学会雑誌，日本内分泌学会雑 誌, 日本公衆衛生学雑誌, 日本内科学会雑誌 日本農芸化学会誌，日本之医界，日本温泉気 候学会雑誌，日本臨床，日本臨床外科医会雑 誌, 日本臨床結核, 日本産科婦人科学会雑誌 日本泌尿器科学会雑誌, 日本産婦人科学会雑 誌, 日本法医学雑誌, 日本医師会雑誌, 日本 細菌学雑誌, 日本胸部外科学会雑誌, 日本血 液学会雑誌, 日本輸血学会雑誌, 日本生化学 会及報, 日本生理学雑誌, 日本赤十字社病院 年報, 日本歯科学会雑誌, 日本小児科学会杂住 誌，日本薬物学誌誌，日本鉄道医学会雑誌， 日本菓洋医学会誌，日本薬報，日本楽理学記 事, 日本薬理学雑誌, 新潟医学会雑誌, 日本 薬戍師協会雑誌, 日本循環器学会誌, 日本耳 鼻喉师科雑誌，日本循環器病学誌，日独医学 日独治療, 日赤医学, 内科端函, 内内泌, 日 仏医学輯報, 日新医学, 日新治療, 日大医学 雑誌, 脳と神経, 日本大学歯学部紀要, 日本 大学農獣医学部学術研究報告, 日本馬事新報 Nagoya J. of Med. Sci.

Nagoya Med. I.

National Institute of genetics, annual report. Nihon Univ. J. of Med.

o）岡山医学会雑䚾，岡山医科大学紀要， 大阪大学医学雑誌, 大阪大学歯学雑雑誌, 大 阪医学会雑誌，大阪附立衛生研究所報告，大 阪医学雑誌、大阪医科大学雑誌，大阪高等医 学専門学校生理学論文集, 大阪方立医科大学 雑誌, 大阪帝国大学医学部研究本績年報, 大 阪常国大学医学部研究本績集, 大阪帝国大学 医学部研究報告, 大阪檤科学会雑誌歯科医学 大阪女子医科大学雑誌, 温泉科学, 乙卯研究 所年報，扣茶の水医学雑誌，小樽医事研究会 誌, 温研紀要 
Osaka City Med. J.

p）ベニシリンその他抗生物質，ペニシリ ン

Pharmaceut Bull.

Proc. Nat. res. council of Japan.

Proc. of the Imp. Acad. of Japan.

Proc. of the Imp. Pharmacol. Soc. Tokyo.

Proc. of the Jap. Physiol. Soc.

Proc. of the Jap. Acad.

r）理化学研究所報告, 臨怵と研究, 臨床 と治碎，臨休と楽物，臨床内科小児科，臨床 眼科, 学働科学, 学働科学研究所年報, レプ ラ,リウマチ

s）診断, 診断と治療, 精神神経学雑誌, 最近学, 最新治療, 性病, 産媂人科の実際 産科之福人科, 札幌医学雑誌, 成医会雑誌, 生化学，生体の科学，四国医学会誌，塩野義 研究沂作, 四国医学雑誌, 島根医学, 生物 物理化学, 生薬学雑誌, 新医薬観, 信州医学 雑誌, 小児科紀要, 信州大学紀要, 新楽と臨

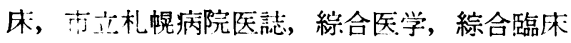
上淮自然科学研究所郸報, 昭和医学会雑誌, 昭和孯呌大学紀要, 手術, 兴学, 歯科月報, 荘太医学:会雑誌

Scientific reports from the Gov. inst. for infect diseases of Tokyo Imp. Univ.

t）演峰研究所年報, 台北医学専門学校々 友会襍拄，台北医院年報，大邱医学専門学校 雑誌，台北医学専門学校楽物学教室論文集, 台湾宾学会誌, 珷田研究所年報, テラピー, 治療, 治療学雑誌, 治療医学, 治療及処方, 治療辈法, 䣓国女子医学雑誌, 東亜医学, 東 邦医学襍誌, 糖尿病, 東北医学雑誌, 東北実 験医学, 徳鼠県医学会雑誌, 東京文理科大学 理科報告, 東京医学会雑誌, 東京女子医科大 学雑志，迎信医学，刀根山シンポジウム，東 京医利大学雑誌，東京医学専門学校雑誌，東 京医事新誌，東宗市駒込病院報告，東京帝国 大学医学部紀要, 東京接恵会医科大学雑誌,
東京慈恵会医科大学解剖業績集, 東洋医学雑 誌, 東京都立衛生研究所年報, 富山県売薬試 験場報, 富山薬学専門学校集報, 東西医学, 中外医薬, 中外医事新報, 中央医学, 東京薬 科大学研究所年報, 東北楽科大学紀要, 徳島 大学楽学部研究年報

Tohoku J. of Exp. Mek.

Transactions of the Sizenkagaku Kenkyusyo. The Tokushima J. of Exp. Med.

w) 和歌山医学

Wakayama Med. Reports.

y) 薬学, 薬学研究, 薬学雑誌, 横浜医学 米子医学雑誌, 薬局, 薬局の領域, 山口医学 Yokohama Med. Bull.

Yonago Acta Medica.

z）耳鼻咽咽科，耳鼻喉咽科臨床，㫛科雑 誌, 実験医学雑誌, 実験消化器病, 実験治療 実験楽物学雑誌, 実践医理学, 順天堂医事研 究会雑誌, 順天堂医学雑誌, 十全会雑誌, 十 全医学会雑誌, 仁家医学

\section{2. 外国 \\ a. 抄録案引}

Abstracts of bacteriology. (Society of American bacteriologists). (Baltimore)

Abstracts of chemical papers. (London)

British chemical Abstracts.

Biological Abstracts. (Philadelphia)

Chemical Abstracts. (Ohio)

Chemisches Zentralblatt.

Excepts Meeica. (Amsterdam)

Index Medicus. (Washington)

Medical j. abstracts. (New York)

Medical science abstracts and reviews.

(London)

Medical times. (New York)

Pharmaceutical j.; the official organ of the

Pharmaceutical Society of Great Briten.

(Liver-pool, London)

Pharmazeutische Rundschon. (New York)

Pharmazeutische Zentralhalle fur Deutschl- 
and. Dresden-Leipzig)

Quartery index to Current Medical Literature.

World medicine.

Zentralblatt fur Biochemie u. Biophysik, mit Einochluss d. theoritischen Immunitatssorschung.

Zentralblatt der experimentellen Medezin. (Berlin)

Zentralblatt fur die gesamte Tuberkuloseforschung.

Zentralblatt fur Physiologie.

\section{b. 綜 説}

Advances in biological and Medical Physics. (New York)

Adovances in enzymology and related Subject of biochemistry. (New York)

Annual review of biochemistry. (Stanford University, Calif.).

Annals of the New York Academy of Science.

Annual review of medicine. (Stanford, Calif.)

Biological Reviews.

Chemical Reviews.

Ergebnisse der Physiology und experimentellen Pharmakologie. (Munchen-Wies baden)

Fortschritte der Medizin. (Berlin)

International Medical Digest.

Tahresbericht Physiologie und experimentelle Pharmakologie. (Munden)

Pharmacological reviews. (Baltimore)

Physiological reviews. (American Physiological Society.) (Baltimore)

Progres Medical. (Paris)

\section{c. 雑 誌}

Abhacdlungen zur theoretischen Biology. (Berlin)

Acta argentina de fisiolagia y fisiopatologia. (Cordoba)

Acta cardiologica. (Bruxelles)

Acta endocreinologica. (Copenhagen)

Acta medica scandinavica. (Stockholm)

Acta neurovegetation. (Winn)
Acta Pharmaceutica internationalis. (Copenhagen)

Acta Pharmacologica et toxicologica. (K $\phi$ benhavn)

Acta Physica Polonica. (Warszawa)

Acta Physiologica et Pharmacologica neerlandica. (Amsterdam)

Acta Pdysiologica Scandinavica.

Archivio di farmacologia Sperimentale e scienzeaffini. (Roma)

Arztliche Forschung Bad Worischofen. (Germany)

Arztliche Rundschau. (Munchen)

Arztliche Wochenschrift. (Berlin)

Arzneimittel-Forschung. (Stocknolm)

Arztliche Central-Zeetung; Fachwissenschaftliches J. and Organ fur die Gesamtinteressendes Arztlichen Standes. (Wien)

Ameri. J. of Cardiology.

Ameri. J. of Medicine. (New York)

Ameri. J. of Pharmacy. (Philadelphia)

American journal of Physiology. (American Physiological Society.) (Boston-Baltemore)

Anaesthesia. (London)

Anaesthesist. (Berlin)

Anaesthesiology.

Anales de la Facultad de Medicina.

Anales de la Facultad de Medicina Montevideo.

Analitica chimica acta; international j. dealing with every branch of analytical chem. (New York)

Anesthesie et anslgésie. (Paris)

Annass de Medecine; resueile Menstiei de mémoires originaaux et revue critiques. (Paris)

Annales de physiologie et Physicochemie biologique.

Annals of internal Medicine. (Lancoster)

Annual report of the board of regents of the Smithsanian institution. (Washington)

Arbeiten aus dem Biochemischen Laboratorium der Hochschule Stockholm. (Wiesboden)

Arbeiten aus dem Pharmakologischen Institut der Marburgar niversität. (Marburg) 
Arbeiten aus dem Pharmakologischen Institut der Universität. (Wien)

Archiv der Pharmazie und Berichte der Deutschen Pharmazeutischen Gesellschaft. (Berlin)

Archiv. f. Toxikologie.

Archives of biochemistry and biophysics. (New York)

Archives Générales de médicine. (Paris)

Archives of internal médicine. (Chicago)

Archives internationales de Pharmacodynamie et de thérapie. (Paris)

Archives de médecine des enfants. (Paris)

Archives de médecine et de Pharmacie navales. (Paris)

Archives de Pharmacolodynamie. (Paris).

Arzneimittel-Forschung. (Auenborf)

Australian journal of experimental biology and medical Science. (Adeloide)

Beiträgs zur ärztlichen Praxis.

Bericht der Deutschu Pharmazeutischen Gesellschaft. (Berlin)

Berichte über die gesamte Physcologie und experimentalle Pharmakologie. (Berlin)

Bericht der Naturwissenschaftlichen Gesellschaft zu Chemnitz. 同会 Abhandlungen を会古.

Bericht der Pharmaceutischen Gesellschaft. (Berlin)

Biochemical journal. (Biochemical Society)

(Liverpool-Cambridge)

ochemical Pharmacology.

Biochemische Zeitschrift.

Biological reviews of the Cambridge. Philosophical Society. (Cambrige University)

Biol. Bull. Woods Hole.

British J. of Pharmacology and Chemotherapy. (London)

Bulletin of the New York Academy of medicine.

Bulletin of the World Health Organization.

British medical, j.

Calcutta medical journal.

California and western medicine (San Fran- cisco)

Canadian j. of biochemistry and Physiology. (Ottawa)

Cardiologia.

Chemische Berichte. (Berlin-Weinheim, Germ.)

Chinese medical journal. (Shanghi)

Girculation.

Circulation Research.

Collectance pharmaceutica succica. (Stockholm)

Compt Rendue Soc. Biol. (Paris)

Compt Rendue Acad. Sci. (Paris)

Courier of Medicine. (St. Louis)

Cronica Médica. (Lima)

Deutsch-Amerikanische Apotheker-Beitung. (New-York)

Deutsche-Aerzte-Zeitung. (Berlin)

Deutsche Medizinal-Zeitung. (Berlin)

Deutsche Mediziniscne Wochenschrift. (Leipzig)

Drug and cosmetic industry. (New-York)

Endokrinologie. (Leipzig)

Ergebnisse der gesamten Mecizin. (Berlin( Experimentia.

Experimentat Biology and Medicine. (New York)

Federation Proceeding.

Helvetica chimica acta. (Genéve)

Helvetica medica acta. (Bosel)

Helvetica physiol acta.

Hoppe-Seylers Zeitschrift für Physiologische Chemie. (Berlim)

Index of New Products used in Medicine. (England)

Illinois medical journal. (Springfield I)

Indian journal of medical research. (Calcutta) International congress of medicine. (Paris, Wien, Washington, etc.)

Jahresbericht der Pharmazie. (Göttingen) 
Journal of the American Pharmaceutical asso siation. (Easton. Pa.)

Journal of Applied Physiology.

Journal of biological chemistry. (Baltimore) Journal of clinical endocrinology and metabolism. (Springfield)

Journal of of clinical investigation.

Journal médical francais. (Paris)

Journal of gen. Physiol.

Journal of medical research. (Boston)

Journal of medicine. (Cincinati)

Journal of Neurophy-sology. (Ilinois)

Journal of Neurochemistry. (Pregamon Press

New York, Oxford, Paris)

Journal de pharmacie et de chimie. (Paris)

Journal de Physiologie. (Paris)

Journal of Pharmacology and experimental therapentics. (Baltimore)

Journal der Pharmacie fur Ärzte, Apotherker und Chemisten. (Leipzig)

Journal of Pharmacy and Pharmacology. (London)

J. für Pharmakodynamik, Toxikologie und Therapie. (Halle)

J. of the Philippine Islands Medical Association. (Manila)

Klassiker der Medizin. (Leipzig)

Kongresszentralblatt für die gesamte innere

Medizin und ihre Grunzgebiete. (Berlin)

Lancent. (London)

Marseille-Médical.

Médecine. (Paris)

Médecine-Sciences. (Par!s)

Medica. (Cuba)

Medical arts and Science. (Los Angeles)

Medical J. of Australia. (Sydney)

Medical J. of South Africa. (Johannasburg)

Medical notes Cincinnati.

Medical life. (New York)

Medical news. (New York)

Medical record. (New York)

Medicina: reuista mensual de chiencias medicas. (Modrid)
Medicina. (Mexico)

Medicina aragonesa- (Zaragoza)

Morck's annual report of recent advances impharmaceutical chemistry and therapeutics. (Darmstadt)

Merck's wissenschaftliche Abhandungen aus den Gebietender der Pharmakotheropie, Plarmazie und verwandter Disziplinen. (Darmstadt)

Medizinische. (Stuttgort)

Medizinische Welt. (Berlin)

Modean medicine. New York)

Münchener medizinische Wochenschrift. (München)

Nature. (London)

Naunyn-Schnieldberg's Archiv für experimentelle Pathologie und Pharmakologie. (Leipzig)

New England J. of medicine. (Boston)

Pharmaceutica acta Helvet al. (Zürich) (Schweizerische Apothekerzeutung の附録)

Pharmaceutical J.; the official organ of the Pharmaceutical Society of Great Berlin. (Liuer-pool, London)

Phaamaceutisch tijdschrift voor Neberlandschlandië. (Welterenden)

Pharmaceutisch weekblad voor Nederland. (Amsterdam)

Pharmacodynamie et de Thérapie. (Bruxebles)

Plarmacy international. (New York)

Pharmakologische Beiträge zur Alkoholfrage. (Jena)

Pharmacology and Toxicology (trans. of Russian J). (America)

Pharmazeutische Post. (Wien)

Pharmazeutische Press. (Wochenschrift für die Wissenschoftlichen und wirtschaftlichen Interessen der Pharmazie. (Wien)

Pharmazeutische Zeilschsift für Russland. (St. Petersburg)

Pharmazeutische Zeitung; Zeitschrift für die Wissenschaftlichen und Praktischen Angelegenheiten des deutschen Apothekes. 
(Berlin)

Pharmazeutische Zeitung-Nachrichten. (Homburg)

Pharmazeutischer Kalender. (Berlin)

Pille; Illustréeste Monatsblätter der Apotheker-Zzitung. (Leipzig)

Press medical. (Paris)

Proc. Soc. exp. Biol \& Med.

Proc. Royal Soc.

Psychopharmacologia.

Quarterly J. of medicine. (Oxford)

Quarterly J. of Pharmacy and Pharmacology. (London)

Reichs-Medicinal-Anzeiger. (Leipzig)

Reuista de la Asociation médica argentina.

Reuista Brazileira de medicona e pharnacia. (Riode Janeiro)

Revue de pharmacologie et de thérapeutique expérimentate. (Paris)

Sammlung von Tergiftungsfëllen. (FühnerWieland) (Leipzig-Berlin)

Schweizerische Medizinishe Wochenschrift.

Science. (Mas.)

Sitzungsberichte der Physikalisch-Medizinischen Sozietät zu Erlangen.
South Africa J. of medicaj sciences.

(Jokannesburg)

Studies from the Rockefeller institute for medical research. Reprint. (New Nork)

Texas state J. of medicine. (Fort Worth)

Thérapeutique médicale. (Paris)

Therapie der Gegenwart. (Berlin-Wien)

Toxicology and applied Pharmacology.

Transactions of the America medical association. (Philadelphia)

Union Pharmaceutique; et le Bulletin commercial riunis. J. de la Pharmacie cenrale de France. (Paris)

Vierteljahresschrift für Praktische Pharmazie. (München)

Virchows Archiu für Pathologische Anatomie und Physiologie und für Klinische Medizin. (Berlin)

Zeitschrift für experimentelle Pathologie und Therapie. (Berlin)

Zeitschrift für die gesamte experimentelle Medizin. (Berlin)

Zeitschrift für Krebsforschung.

\section{滆末 町}

橋田邦拦先生好みの正法眼蔵会が，山形の 八邪であった時, 後に駒沢大学長にもなった 伊豆修善寺の丘宗潭師に，1ケ月ばかりアン ジャ行者をして，聴講したことがある。その ときの話に，中国の偉い禅僧が，書物をかい たが何人かにぬすまれた。弟子たちはやかま しくさわいだが見つからない。それがいつの 間にか, 立派な著述となって, 別人の名で出 版された。禅僧がいうことには，木材をつく るカンナ屑だ，人体をつくる屎のようなもの た，学行の洋である。それでも人のためにな るというのなら, 誰が出してもよかろう, と いったような意味のものだった。これが年少
の頭にこびりついていたが，いまだにその名 も出典もわからないままである。

戦時戦後，東大の司書官であった，フラ ンス文学の水野亮さんから, 君も随分烧いた 䘛いわれたが, 東宗最後の爆撃で賤家も一 挙に焼けてしまった。手の施しようもないま ま，図書類もそっとしておいたら，1日て然 えきれなかった。図書はとにかく書きためて いた文献や索引類を，みんな焼いてしまった ので，筆とるのを断念したのであった。水野 さんからは，慶長ごろのキリシタン文書を頂 いたこともあるが，全国著名図書館の図書分 類表を譲られて，書庫においていたが，いつ の間にか紛れてしまった。 $\times \times \times$ 